\title{
INVESTIGATING THE EFFECT OF HYGROSCOPICITY OF AEROSOLS ON OPTICAL PROFILES OF PBL OBSERVED BY DUAL-WAVELENGTH LIDAR
}

\author{
Wei-Nai Chen ${ }^{1}$, Yung-Chang Chen ${ }^{2}$, Hui-Ming Hung ${ }^{2}$, M. Roja Raman ${ }^{3}$ \\ ${ }^{1}$ Research Center for Environmental Changes, Academia Sinica, Taipei, Taiwan. \\ E-mail: wnchen@rcec.sinica.edu.tw \\ ${ }^{2}$ Department of Atmospheric Science, National Taiwan University, Taipei, Taiwan. \\ E-mail: hmhung@ntu.edu.tw \\ ${ }^{3} U G C$ - SVU Centre for MST Radar Applications, $S$ V University, Tirupati, Andhra Pradesh, India. \\ E-mail: ramansvu@gmail.com
}

\begin{abstract}
The light scattering and radiation properties of aerosols are mainly dominated by hygroscopicity. In this study, the relationship between the wavelength dependent ratio of lidar scattering signals (color ratio) and relative humidity and the application of the color ratio to identify the cloud base is examined.
\end{abstract}

\section{INTRODUCTION}

Changes in aerosol scattering properties can highly influence the Earth's climate by affecting the Earth's radiation budget. The knowledge of the direct and indirect interaction of atmospheric aerosols on climate is still quite low compared to other atmospheric constituents, not only due to high spatial and temporal variability of aerosols but also due to hygroscopicity. In the ambient atmosphere, the aerosol particles may absorb moisture from the surrounding air and increase their size causing significant change in their size distribution and their associated optical and microphysical properties[1].

In previous studies we already noticed that the interrelationship between the aerosol Angström exponent and particle depolarization can reveal information on particle size and shape [2]. In that study, it was reported that the aerosol hygroscopicity might be the reason for the observed distortion in the linear correlation between Ångström exponent and particle depolarization. In this study, we try to combine Mie scattering theory and Köhler theory to study the effect of aerosol hygroscopicity on PBL profiles. We also try to use the lidar color ratio $(\mathbf{C R})$ as indicator of particle size to investigate the inter-relationship between color ratio, hygroscopicity $(\kappa)$, and relative humidity.

\section{METHOD}

\subsection{Color Ratio}

The particle size can be inferred from size-dependent light scattering properties such as the Ångström exponent and color ratio [2; 3; 4] (and references therein). The Ångström exponent had been wildly used to understand the particle size. However, the Ångström exponent might be highly uncertain or unavailable because the value of the Angström exponent highly depends on the accuracy of lidar inversion. Therefore, the ratio of lidar backscatter at different wavelengths (color ratio) might be a simple indicator and more suitable than the Ångström exponent for Planetary Boundary Layer (PBL) studies.

In this study, vertical profiles of lidar backscatter measured by Research Centre for Environmental Changes / Academia Sinica and National Taiwan University (RCEC/ASNTU) Lidar installed in National Taiwan University, Taipei, Taiwan is used for a case study. The RCEC/ASNTU Lidar is a dual wavelength depolarization lidar operated at $355 \mathrm{~nm}$ and $532 \mathrm{~nm}$ designed to measure aerosols and clouds up to $10 \mathrm{~km}$ during day and $20 \mathrm{~km}$ at night[2]. The particulate backscatter color ratio $\mathbf{C R}$ is defined as

$$
C R=\frac{P_{532}}{P_{355}}
$$

where $P_{532}$ and $P_{355}$ are particulate backscatter at 532 and $355 \mathrm{~nm}$ respectively.

\subsection{Hygroscopicity}

The saturation ratio of a liquid aerosol droplet in aerosol in its volume equivalent diameter, $S_{e q}$ [5], over an aqueous solution droplet can be calculated from

$$
\begin{aligned}
S_{e q} & =a_{w} \times e^{A / D} \\
a_{w} & =\frac{n_{w}}{n_{w}+i n_{s}} \\
A & =\frac{4 \sigma_{w} M_{w}}{\rho_{w} R_{v} T}
\end{aligned}
$$

where $a_{w}$ is the activity of water in solution, $\rho_{w}$ is the density of water, $M_{w}$ is the molecular weight of water, $\sigma_{w}$ is the surface tension of the solution/air interface, $R$ is the universal gas constant, $T$ is temperature, and $D$ is the diameter of the droplet, $D_{d}$ is the dry diameter.

For a multicomponent system (multiple solutes + water) at equilibrium, Eq. 2 yields the equation defining $\kappa-$ Köhler theory

$$
S_{e q}(D)=\frac{D^{3}-D_{d}^{3}}{D^{3}-D_{d}^{3}(1-\kappa)} \times \exp \left(\frac{4 \sigma_{w} M_{w}}{\rho_{w} R_{v} T D}\right)
$$

Where $\kappa$ can then be understood as expressing the volume (or mass or moles, with appropriate unit conversions) of water that is associated with a unit volume of 
dry particle.[5] The overall value for $\kappa$ is given by the simple mixing rule

$$
\kappa=\sum_{i} \varepsilon_{i} \kappa_{i}
$$

The wavelength dependent backscattering coefficient of grown particles can be calculated using

$$
\beta(\lambda)=\frac{\pi D^{2}}{4} N_{d} Q_{b a c k}(\lambda)
$$

where $N_{d}$ is volume number density of particle and $Q_{\text {back }}$ is the backscattering efficiency calculated from Mie theory with complex refractive index. In this study, $m=$ $1.44+0.43 i$ is used for most of the simulation.

In general, the value of $\kappa$ for soluble inorganic aerosols is in the range 0.4-1.4; for organic aerosols it is in the range of 0.01-0.5 and for black carbon is less than 0.01.

Our previous studies found $\kappa$ is around 0.2 for aerosols in Taipei City and 0.1- 0.2 for aerosols in Kaohsiung City [6].

\section{RESULTS}

\subsection{Hygroscopic Growth}

Figure 1 shows the typical particle size distribution (solid black) observed in Taipei. The hygroscopic growth size distributions from $d r y$ to $\mathrm{RH}=98 \%$ for aerosols with $\kappa=0.2$ (solid blue) and 0.61 (dashed black) are shown for comparison. Particles with $\kappa=0.61$ are about two times larger than particle with $\kappa=0.2$ when $\mathrm{RH}=98 \%$.

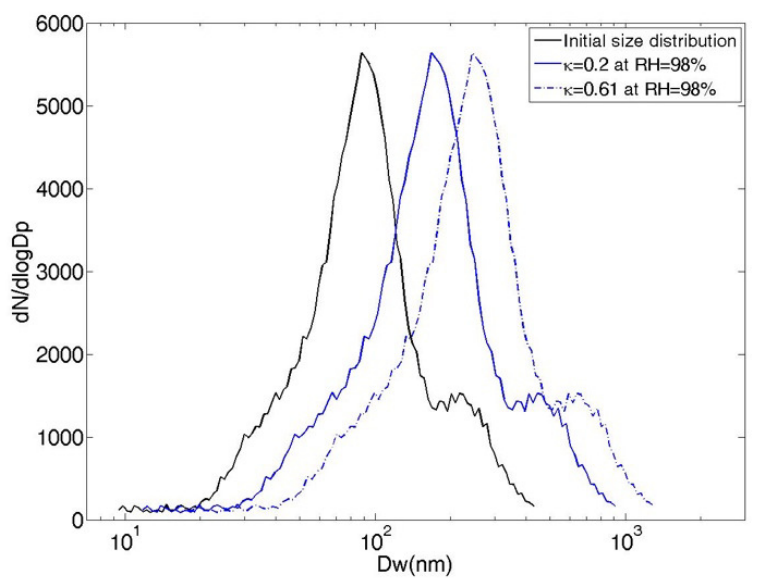

Figure 1: Dry particle size distribution (solid black) and hygroscopic particles growth from "dry" to $\mathrm{RH}=98 \%$ for particles with $\kappa=0.2$ (solid blue) and 0.61 (dashed blue).

The corresponding backscattering coefficient as a function of $R H$ for aerosols with $\kappa=0.2$ is shown in Fig. 2. The complex refractive index of aerosol is set to $m=$ $1.44+0.043 i$. Here the Particle Backscatter Coefficient (PBC) or $\beta_{\text {par }}$ increases slowly with increase in $R H$ up to $\mathrm{RH}<80 \%$. After $\mathrm{RH}$ is higher than $80 \%$, the $\beta_{\text {par }}$ increases rapidly with increase in $\mathrm{RH}$. At $\mathrm{RH} \approx 98 \%$ the backscatter is about 10 times larger than the backscatter at $\mathrm{RH}=40 \%$.

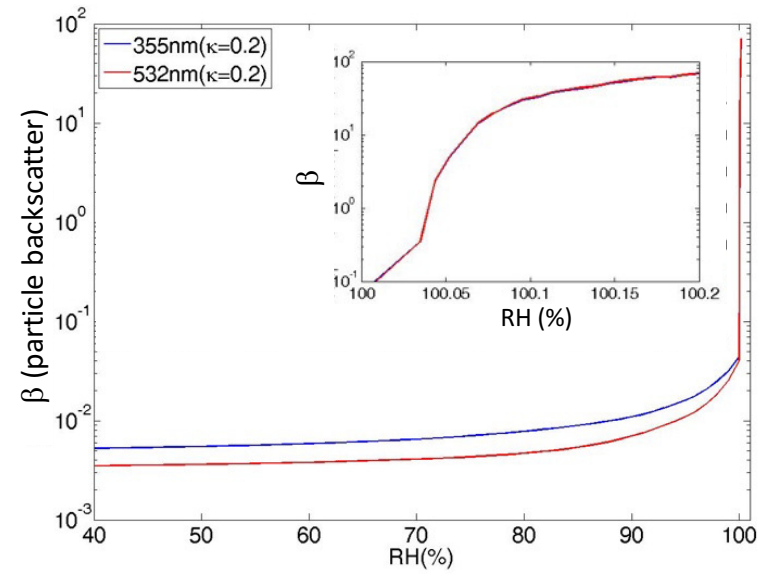

Figure 2: Hygroscopic growth of backscatter with varying $R H$ for aerosols with $m=1.44+0.043 i$ and $\kappa=0.2$.

\subsection{Color Ratio vs. RH}

The calculated color ratio $\mathbf{C R}$ for different $R H$ is shown in Fig. 3. It can be noticed here that the color ratio shows opposite tendency at lower and higher $\mathrm{RH}$ s, respectively. In general, the value of the color ratio is about 0.5 for dry particles. The color ratio slightly decreases with increase in $R H$ from "dry" condition to a critical $R H_{T}$ about $50 \%$ $(\kappa=0.2), 60 \%(\kappa=0.4)$, or $75 \%(\kappa=0.61)$. If $R H$ is larger than $R H_{T}$, the color ratio turns to increase rapidly with increase in $R H$ and reaches a maximum $C R$ of $\sim 0.7-0.8$ at $R H \approx 95 \%$. This result implies a $\kappa$-dependent turning point $R H_{T}$ might be useful as an indicator of $\kappa$.

\subsection{Case Study}

A case observed on 13 January 2009 is selected to simulate and investigate the impact of hygroscopic growth. Fig. 4 shows the time-height evolution of range corrected signal $\left(P \times z^{2}\right)$ for $532 \mathrm{~nm}$ observed by RCEC/ASNTU lidar. The height of boundary layer is about $1.5 \mathrm{~km}$ throughout the day. The height of mixed layer was determined using gradient algorithm [7] and is around $1 \mathrm{~km}$ from $00 \mathrm{Z}-06 \mathrm{Z}$ and decreased to $700 \mathrm{~m}-500 \mathrm{~m}$ after $06 \mathrm{Z}$.

A radiosonde was launched on 13 January 2009 at $00 Z$ to measure the vertical profile of atmospheric parameters. The profile of measured $R H$ is shown in Fig. 5. Based on this $R H$ profile, the relative backscattering coefficients for $355 \mathrm{~nm}$ and $532 \mathrm{~nm}$ are calculated and shown in Fig. 6. Aerosols are assumed being well mixed and hygroscopic growth follow the $\kappa$-Köhler theory. The initial size distribution is shown in Fig. 1. The complex refractive index of dry aerosol is set to $m=1.44+0.043 i$ and $\kappa$ is 0.2 (the typical value of $\kappa$ observed in Taipei [6]). 


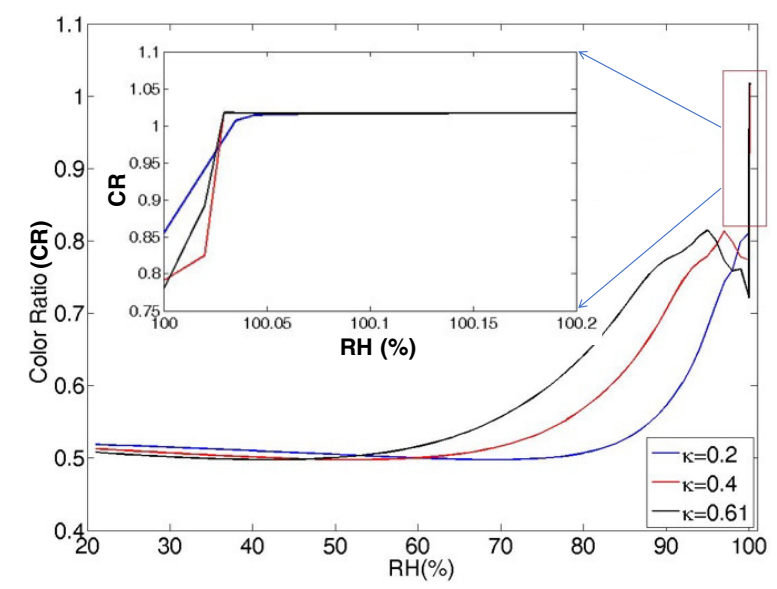

Figure 3: Calculated Color Ratio for different $R H$ for aerosols with $\kappa=0.2$ (black), 0.4 (red), 0.61 (blue) and complex reflectivity $m=1.44+0.043 i$.

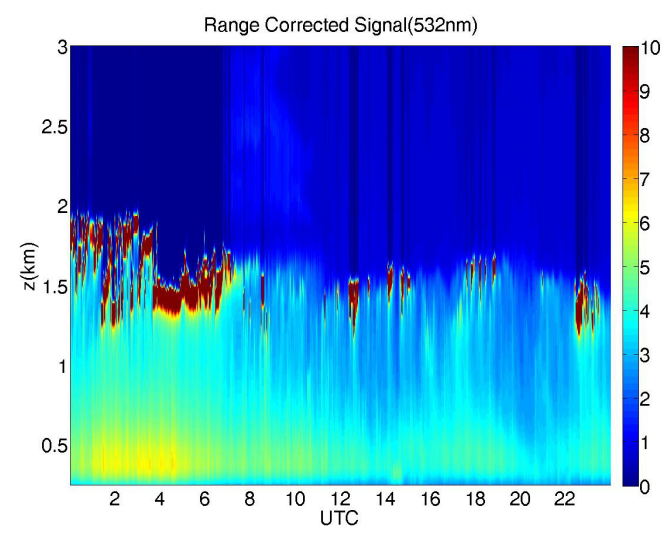

Figure 4: Time-height variation of RCEC/ASNTU Lidar range corrected signal (RCS) at $532 \mathrm{~nm}$ observed on 13 January 2009 at Taipei

As shown in Fig. 5, $R H$ was about $55 \%$ at ground level. $R H$ gradually increased with height and reached $\mathrm{RH}=98 \%$ at height $z \approx 1.25 \mathrm{~km}$. A small inversion in $R H$ was found at $z \approx 0.8 \mathrm{~km}$, which has been smoothed (dashed green) for hygroscopic simulation. The simulated lidar backscattering coefficients for two wave lengths are shown Fig. 6. Backscattering coefficients for $355 \mathrm{~nm}\left(\beta_{355}\right)$ and $532 \mathrm{~nm}\left(\beta_{532}\right)$ at ground level $(z=0)$ are about 0.005 and $0.003 \mathrm{~m}^{-1} \mathrm{sr}^{-1}$, respectively. $\beta_{355}$ and $\beta_{532}$ slightly increase with height up to $z \approx 1 \mathrm{~km}$ or $\mathrm{RH} \approx 90 \%$. $\beta_{355}$ and $\beta_{532}$ turn to rapidly increase to 0.04 $\mathrm{m}^{-1} \mathrm{sr}^{-1}$ when $\mathrm{RH} \approx 98 \%$. Beyond $\mathrm{RH}=98 \%$, aerosols are activated as cloud droplets and the corresponding $\beta_{355}$ and $\beta_{532}$ increase to 55 at $z \approx 1.4 \mathrm{~km}$, which are about 1000 times higher than $\beta_{355}$ and $\beta_{532}$ at surface level.

The height distribution of observed (solid red) and calculated (solid blue) color ratios are shown in Fig. 7. The observed CR decreases from 0.6 to 0.4 with height in-

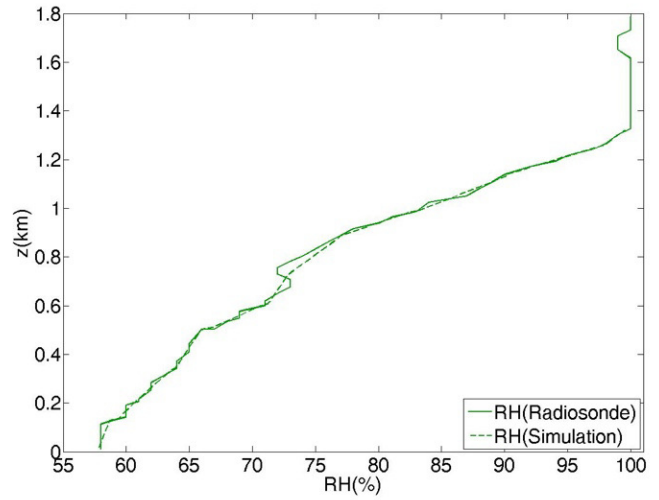

Figure 5: Radiosonde measured (solid green) $R H$ profile on 13 January 2009 at $00 \mathrm{Z}$. Smoothed $R H$ profile (dashed green) used for hygroscopic simulation.

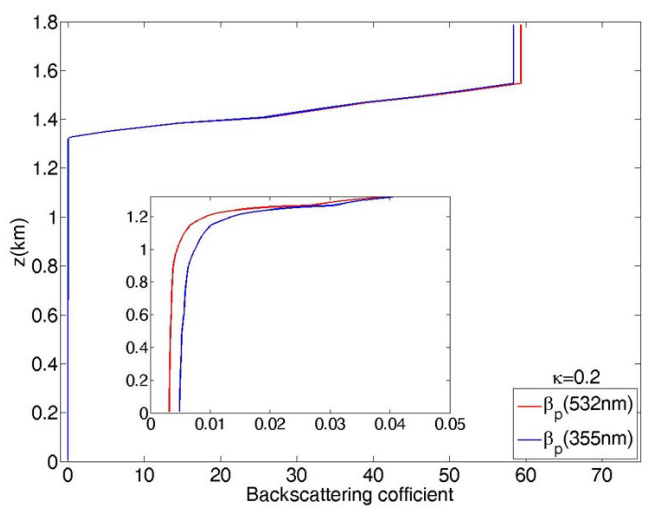

Figure 6: Simulated lidar backscattering coefficients for $355 \mathrm{~nm}$ (blue line) and $532 \mathrm{~nm}$ (red line) with $\kappa=0.2$ and $m=1.44+0.043 i$. The initial size distribution is shown in Fig. 1 and $R H$ profile is shown in Fig. 5.

creasing from surface level to $1.3 \mathrm{~km}$. CR turns to rapidly increases from 0.4 to 1.4 with height (or $\mathrm{RH}$ ) increasing from $1.3 \mathrm{~km}$ to $1.4 \mathrm{~km}$. The calculated CR slightly increases from 0.42 to 0.6 with height increasing from surface level to $1.2 \mathrm{~km}$. The calculated $\mathbf{C R}$ turns rapidly increases from 0.6 to 1 with height increasing from 1.2 $\mathrm{km}$ to $1.3 \mathrm{~km}$.

The similarities and discrepancies between observation and simulation can be noticed here. The calculated $\mathbf{C R}$ starts to rapidly increase at lower $R H$ than observed CR. The vertical structures of observed and calculated $\mathbf{C R}$ are much different between $1.3 \mathrm{~km}$ and $1.5 \mathrm{~km}$. This discrepancies might be owing to incorrect $\kappa$ value or RH. Fig. 8 shows the calculated $\mathbf{C R}$ profiles based on the $R H$ profile (dashed blue) modified from radiosonde measurement (solid green) to match the observed $\mathbf{C R}$. This result shows, a small uncertainty would cause large difference from reality. Another implication from Fig. 7 and Fig. 8 is $\kappa$ might be over estimated. It can be noticed that the 
simulated $\mathbf{C R}$ profile with $\kappa=0.1$ is more closer to lidar observation.

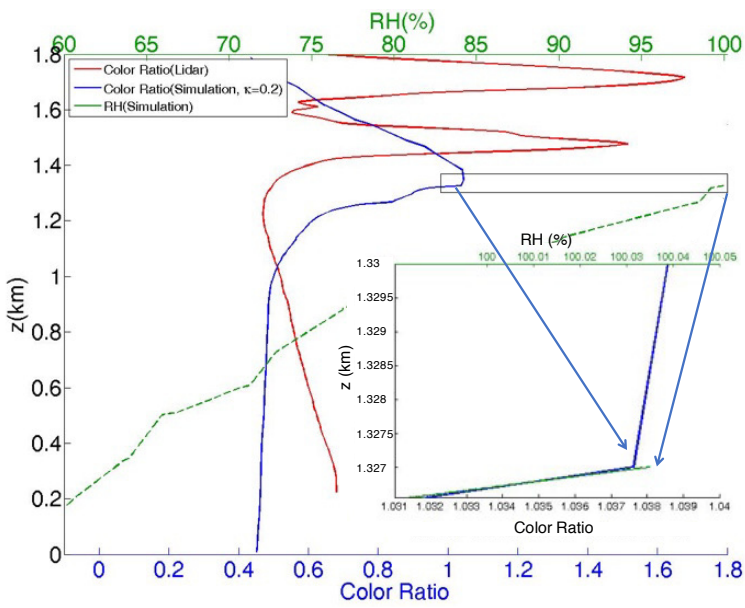

Figure 7: Observed (red) and simulated (greed) vertical profile of Color Ratio (CR) with $\kappa=0.2$ and $R H$ profile (blue) observed by radiosonde.

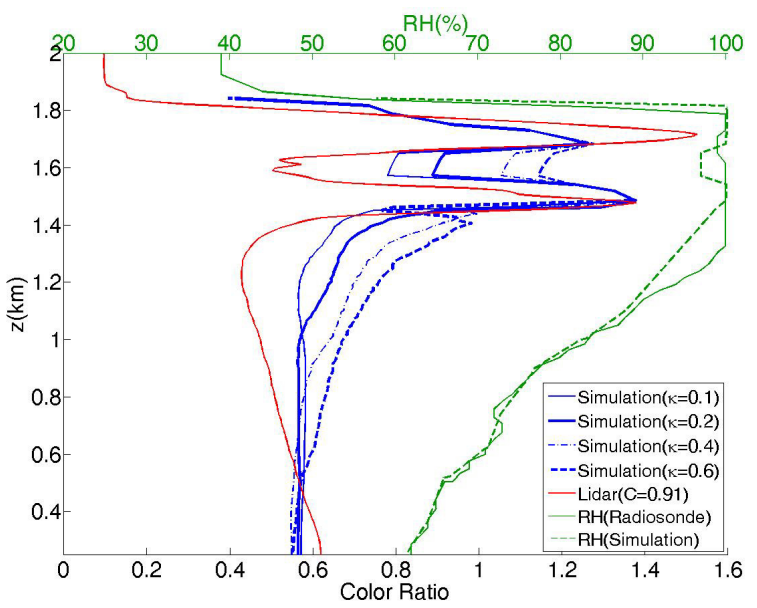

Figure 8: Same as Fig. 7 but with various $\kappa$ and modified $R H$ profile (blue).

\section{SUMMARY}

- In general, CR of "dry" particle slightly decreases with increase in $\mathrm{RH}$ from $0 \%$ to a critical $\mathrm{RH}_{T}$ about $60 \%(\kappa=0.2), 70 \%(\kappa=0.4)$, or $80 \%(\kappa=0.61)$. Color ratio turns to increase rapidly with increase in $R H$ when $R H$ is larger than $\mathrm{RH}_{T}$.

- The discrepancies might be owing to incorrect $\kappa$ value or RH. Measured $R H$ is found highly uncertain when $R H$ higher than $95 \%$.

- Considering the value of $\kappa$ about 0.1 can make the simulation and observation more closer but it is lower than typical value of $\kappa$ observed by $\mathrm{CCN}$ counter. More study is needed to reveal the possible reasons. Full investigation will be presented in the conference.

\section{REFERENCES}

1. Fernández, A. J., Apituley, A., Veselovskii, I., Suvorina, A., Henzing, J., Pujadas, M., and Artíñano, B. Study of aerosol hygroscopic events over the Cabauw experimental site for atmospheric research (CESAR) using the multi-wavelength Raman lidar Caeli. Atmospheric Environment, 120(C):484-498, November 2015.

2. Chen, W.-N., Tsai, F., Chou, C., Chang, S., Chen, Y., and Chen, J. Optical properties of Asian dusts in the free atmosphere measured by Raman lidar at Taipei, Taiwan. Atmospheric Environment, 41(36):76987714, 2007.

3. Ansmann, A., Bösenberg, J., Brogniez, G., Elouragini, S., Flamant, P. H., Klapheck, K., Linn, H., Menenger, L., Michaelis, W., Riebesell, M., Senff, C., Thro, P.-Y., Wandinger, U., and Weitkamp, C. Lidar Network Observations of Cirrus Morphological and Scattering Properties during the International Cirrus Experiment 1989: The 18 October 1989 Case Study and Statistical Analysis. Journal of Applied Meteorology, 32(1):1608-1622, October 1993.

4. Liu, Z., Vaughan, M., Winker, D., Kittaka, C., Getzewich, B., Kuehn, R., Omar, A., Powell, K., Trepte, C., and Hostetler, C. The CALIPSOLidar Cloud and Aerosol Discrimination: Version 2 Algorithm and Initial Assessment of Performance. JOURNAL OF ATMOSPHERIC AND OCEANIC TECHNOLOGY, 26(7):1198-1213, July 2009.

5. Petters, M. D. and Kreidenweis, S. M. A single parameter representation of hygroscopic growth and cloud condensation nucleus activity. Atmospheric Chemistry and Physics, 7(8):1961-1971, April 2007.

6. Hung, H.-M., Lu, W.-J., Chen, W.-N., Chang, C.-C., Chou, C. C.-K., and Lin, P.-H. Enhancement of the hygroscopicity parameter kappa of rural aerosols in northern Taiwan by anthropogenic emissions. Atmospheric Environment, 84(C):78-87, February 2014.

7. Flamant, C., Pelon, J., Flamant, P. H., and Durand, P. Lidar determination of the entrainment zone thickness at the top of the unstable marine atmospheric boundary layer. Boundary-Layer Meteorology, 83(2):247284, 1997.

\section{ACKNOWLEDGMENTS}

This study was supported by Taiwan National Science Council (105-2119-M-001-025 and 103-2923-M-001003-MY3). We also thank Academia Sinica, Taiwan for providing Post-doctoral fellowship funded by National Science Council, Taiwan. 